\title{
Heart Rate Variability Is a Predictor of Mortality in Chronic Kidney Disease: A Report from the CRIC Study
}

\author{
Paul E. Drawz ${ }^{a}$ Denise C. Babineau ${ }^{b}$ Carolyn Brecklin ${ }^{c}$ Jiang He ${ }^{d}$ \\ Radhakrishna R. Kallem ${ }^{\mathrm{e}}$ Elsayed Z. Soliman ${ }^{f}$ Dawei Xie $^{g}$ Dina Appleby ${ }^{g}$ \\ Amanda H. Andersong Mahboob Rahman ${ }^{\text {h }}$ CRIC Study Investigators \\ a Division of Renal Diseases and Hypertension, University of Minnesota, Minneapolis, Minn., ${ }^{\mathrm{b}}$ Center for Clinical \\ Investigation, Case Western Reserve University, Cleveland, Ohio, ' Department of Medicine, University of Illinois at \\ Chicago, Chicago, Ill., d Tulane University School of Public Health and Tropical Medicine, Tulane University School of \\ Medicine, New Orleans, La., ${ }^{\mathrm{e}}$ Renal, Electrolyte and Hypertension Division, University of Pennsylvania School of \\ Medicine, Philadelphia, Pa., ${ }^{\text {}}$ Department of Epidemiology and Prevention, and Section of Cardiology, Department of \\ Internal Medicine, Epidemiological Cardiology Research Center, Wake Forest University School of Medicine, \\ Winston-Salem, N.C., ${ }^{9}$ Center for Clinical Epidemiology and Biostatistics, University of Pennsylvania Perelman School of \\ Medicine, Philadelphia, Pa., and h University Hospitals Case Medical Center, Louis Stokes Cleveland VA Medical Center, \\ and Division of Nephrology and Hypertension, Case Western Reserve University, Cleveland, Ohio, USA
}

\section{Key Words}

Autonomic nervous system - Cardiovascular diseases .

Chronic renal insufficiency · Electrocardiography · Mortality

\begin{abstract}
Background/Aims: Low heart rate variability (HRV) is a risk factor for adverse outcomes in the general population. We aimed to determine the factors associated with HRV and evaluate the association between low HRV and clinical outcomes in patients with chronic kidney disease (CKD). Methods: A 10-second electrocardiogram was obtained at baseline in the Chronic Renal Insufficiency Cohort (CRIC) Study. HRV was measured by the standard deviation of all R-R intervals (SDNN) and the root mean square of successive differences between R-R intervals (RMSSD). Results: In 3,245 CRIC participants with available baseline SDNN and RMSSD, lower HRV was associated with older age, lack of exercise, heart failure, elevated phosphorus and hemoglobin A1c, and low estimated glomerular filtration rate. After a median follow-
\end{abstract}

up of 4.2 years, in fully adjusted models, lower HRV was not associated with renal [SDNN: hazard rate, HR $=0.96(95 \%$ confidence interval, Cl 0.88-1.05); RMSSD: $\mathrm{HR}=0.97(95 \% \mathrm{Cl}$ 0.88-1.07)] or cardiovascular outcomes [SDNN: HR $=1.02$ (95\% Cl 0.92-1.13); RMSSD: HR = 1.00 (95\% Cl 0.90-1.10)]. There was a nonlinear relationship between RMSSD and allcause mortality with increased risk with both low and high RMSSD ( $p=0.04)$. Conclusions: In a large cohort of patients with CKD, multiple risk factors for renal and cardiovascular diseases were associated with lower HRV. Lower HRV was not associated with increased risk for renal or cardiovascular outcomes, but both low and high RMSSD were associated with increased risk for all-cause mortality. In conclusion, HRV measured by RMSSD may be a novel and independent risk factor for mortality in CKD patients.

(c) 2013 S. Karger AG, Basel

CRIC Study Investigators: Lawrence J. Appel, MD, MPH; Harold I. Feldman, MD, MSCE; Alan S. Go, MD; Jiang He, MD, PhD; John W. Kusek, PhD; James P. Lash, MD; Akinlolu Ojo, MD, PhD; Mahboob Rahman, $M D$, and Raymond R. Townsend, MD.

\section{KARGER}

E-Mail karger@karger.com www.karger.com/ajn
(C) 2013 S. Karger AG, Basel

0250-8095/13/0386-0517\$38.00/0
Paul E. Drawz, MD, MHS, MS

Department of Medicine, Division of Renal Diseases and Hypertension University of Minnesota

717 Delaware Street SE, Suite 353 E, Minneapolis, MN 55414 (USA)

E-Maildraw0003@umn.edu 


\section{Introduction}

Chronic kidney disease (CKD) is associated with increased sympathetic tone and cardiac autonomic neuropathy, as measured by cardiovascular reflex tests and heart rate variability (HRV) [1-4]. Cardiac autonomic neuropathy manifests as low HRV on standard electrocardiograms (ECGs). The association between CKD and low $\mathrm{HRV}$ is consistent across multiple manifestations of CKD including micro- and macroalbuminuria, decreased estimated glomerular filtration rate (eGFR), and end-stage renal disease (ESRD) [3-9]. A link between CKD and autonomic function is further evidenced by improvement in HRV with treatment of uremia by initiation of dialysis, increasing dialysis frequency, and renal transplantation $[8,10-13]$. In addition to CKD, other risk factors for low HRV include older age, obesity, diabetes, sedentary lifestyle, low high-density lipoprotein (HDL), high insulin, and elevated C-reactive protein and systolic blood pressure [14-18]. Generalizing these findings to patients with CKD is restricted because previous studies were limited by small sample sizes and focused on either mild CKD or on patients with ESRD.

In the general population, lower HRV is associated with increased risk for incident coronary heart disease, cardiovascular mortality, all-cause mortality, and ESRD $[16,19-21]$. Among patients with ESRD [22, 23] and in small studies in patients with CKD $[17,24]$, lower HRV is associated with increased cardiovascular and all-cause mortality and decline in kidney function. Low HRV, a marker for sympathetic activation, may directly contribute to these adverse outcomes by increasing atherosclerosis, vasoconstriction, arrhythmia, sodium retention, renin release, and blood pressure [1]. Therefore, it is reasonable to hypothesize that lower HRV may be an important marker of risk for cardiovascular events and progression of kidney disease, and may contribute to the excess risk of cardiovascular disease seen in the setting of CKD [25]; however, this remains to be established in the setting of CKD among patients with a broad range of GFR.

Therefore, the goal of this study was to determine: (1) the factors associated with low HRV and (2) the association between low HRV measured at study entry and the risk of (a) renal outcomes (defined by ESRD or a $50 \%$ decline in eGFR from baseline), (b) cardiovascular outcomes, and (c) all-cause mortality in a large cohort of individuals with CKD and a broad range of GFR.

\section{Materials and Methods}

The design and baseline characteristics of the Chronic Renal Insufficiency Cohort (CRIC) study have been described previously $[26,27]$. Briefly, CRIC is a multicenter observational study that enrolled patients between June 2003 and September 2008. Participants aged 21-74 years with an eGFR between 20 and $70 \mathrm{ml} /$ $\mathrm{min} / 1.73 \mathrm{~m}^{2}$ were eligible. The study was approved by the institutional review board at each site and all participants provided written informed consent.

The following data were collected at baseline: demographic information, medical history, medication use, blood pressure, anthropometric measures, and serum and urine for laboratory assessments. eGFR was calculated using the re-expressed four-variable equation from the Modification of Diet in Renal Disease [28]. A standard ECG was obtained in all participants. Renal outcomes were defined by a $50 \%$ decline in eGFR or initiation of dialysis or renal transplantation. Cardiovascular outcomes included myocardial infarction, congestive heart failure, and stroke as adjudicated by blinded study investigators using predefined criteria as well as a composite of all three. Participants were followed until death, loss to follow-up, withdrawal from the study, or June 30, 2009.

ECGs were acquired by trained staff members using a standard protocol and GEMSIT (GE Medical Systems Information Technologies) MAC1200 electrocardiographs. Participants were placed in a relaxed, comfortable, supine or semirecumbent position. Paced breathing was not implemented during the ECG recording. ECGs were interpreted in a central ECG center. HRV can be evaluated using standard 10-second ECGs. In normal individuals, heart rate increases and decreases with breathing and in response to changes in blood pressure. The standard deviation of all normalto-normal R-R intervals (SDNN) corresponds to sympathetic and parasympathetic effects while the root mean square of successive differences between all normal-to-normal R-R intervals (RMSSD) corresponds to parasympathetic function [29]. From these definitions, it is important to note that HRV is actually a measure of R-R interval variability. Baseline SDNN and RMSSD were calculated according to current guidelines for all ECGs that had no evidence of atrial fibrillation or any premature atrial or ventricular beats [30]. Participants without baseline SDNN and RMSSD were excluded from the present analyses.

\section{Statistical Analyses}

Participants were grouped by quartiles of SDNN and RMSSD. Baseline characteristics are reported as means and standard deviations or medians and interquartile ranges for continuous variables and frequencies and percentages for categorical variables. Differences between groups were evaluated using ANOVA, KruskalWallis rank sum test, and Pearson's $\chi^{2}$ test, as appropriate. Multivariable linear regression was used to determine the independent factors associated with SDNN and RMSSD, which were log transformed due to a skewed distribution. Covariates previously associated with HRV or with biologically plausible associations with HRV were included in separate multivariable models for SDNN and RMSSD. Variable selection methods were not used due to recognized weaknesses including incorporation of noise variables and excluding authentic predictors [31]. Nonlinearity was assessed using restricted cubic splines. Interaction terms were evaluated. The interaction between eGFR and diabetes was of particular interest 
because the relationship between eGFR and HRV may differ by diabetes status [32]. Linear model assumptions were evaluated by examining residual versus fitted plots, normal Q-Q plots of standardized residuals, scale-location plots, and plots of standardized residuals versus leverage.

Separate multivariable Cox models were used to assess the association between baseline $\log (2)$-transformed HRV and the log relative hazard rate (HR) of: (1) renal and (2) cardiovascular outcomes, and (3) all-cause mortality. For each outcome, three models were constructed for both SDNN and RMSSD. A minimally adjusted model 1 included only age, sex, race, heart rate, and CRIC clinical center. Model 2 assessed whether the relationship between SDNN and RMSSD and adverse outcomes was independent of body mass and renal function and included variables from model 1 plus body mass index (BMI), eGFR, and 24-hour urine protein. Fully adjusted model 3 included variables from model 2 plus systolic blood pressure, education level, tobacco use, lifestyle modification, exercise, angiotensin-converting enzyme inhibitor/angiotensin receptor blocker use, $\beta$-blocker use, hypertension, coronary artery disease, diabetes, congestive heart failure, serum calcium, phosphorus, albumin, and uric acid, fibroblast growth factor (FGF23), low-density lipoprotein (LDL) and HDL cholesterol, triglycerides, and C-reactive protein. Linearity was assessed using restricted cubic splines.

Primary analyses were conducted on participants with complete data. Data were complete for most variables with 24-hour urine protein having the highest percentage of missing values (6.4\%) followed by hemoglobin A1c (4.2\%). Prespecified secondary analyses evaluated whether the relationship between HRV and outcome was modified by age, sex, race, baseline coronary artery disease, diabetes, eGFR, and urine protein. Finally, secondary analysis evaluated whether low HRV was associated with cardiovascular outcomes in participants without a baseline history of myocardial infarction, heart failure, or stroke.

\section{Results}

Of the 3,939 participants enrolled in CRIC, 3,245 who did not have atrial fibrillation, or premature atrial or ventricular contractions on the baseline ECG were included in the present analyses. Baseline characteristics of included and excluded participants are shown in online supplementary table 1 (for all online suppl. material, see www. karger.com/doi/10.1159/000357200). Baseline characteristics by SDNN quartile are shown in table 1. Participants in the lower quartiles were older, had lower education levels, and were more likely to have hypertension, coronary artery disease, heart failure, diabetes, lack of exercise, elevated systolic blood pressure, lower eGFR and albumin, and elevated proteinuria (measured by 24 -hour urine collection), parathyroid hormone, FGF23, hemoglobin A1c, and uric acid. Similar results were observed when baseline characteristics were evaluated by RMSSD quartiles (online suppl. table 2).

Low HRV and Adverse Outcomes in CRIC
Using a multivariable linear regression model, the following characteristics were associated with lower logtransformed SDNN and RMSSD: older age, male gender, non-Hispanic whites (vs. non-Hispanic black/African Americans), heart failure, lack of exercise, use of $\beta$-blockers, elevated phosphorus and hemoglobin A1c, and lower BMI (table 2). The significant associations between HRV and age were nonlinear. The interaction between diabetes and eGFR was significant. Lower eGFR was more strongly associated with lower SDNN and RMSSD in diabetics than nondiabetics. Diabetes was associated with lower SDNN and RMSSD at lower but not at higher eGFR levels. Urine protein was not associated with either SDNN or RMSSD (table 2).

After a median follow-up of 4.2 years, 630 participants (19.4\%) had a renal event, $425(13.1 \%)$ had a cardiovascular event, and $272(8.4 \%)$ died. The first occurrence of clinical outcomes per 1,000 person years by quartile of SDNN and RMSSD is shown in figure 1. The rate of renal outcomes, the cardiovascular composite, and all-cause mortality by quartile of SDNN and RMSSD are shown for descriptive purposes in figures 1 and 2 and online supplementary figure 1 . In models adjusted for age, sex, race, heart rate, and clinical center, both 50\% lower SDNN and RMSSD [a 1-unit decrease in $\log (2)$ SDNN and $\log (2)$ RMSSD, respectively] were associated with an increased relative HR for renal outcomes and the cardiovascular composite (table 3; model 1). Additional adjustment for BMI, eGFR, and proteinuria (model 2) attenuated the associations, but all remained significant with the exception of SDNN and renal outcomes ( $\mathrm{HR}=1.08,95 \%$ confidence interval, CI, 1.00-1.17). In fully adjusted models, lower HRV was not associated with renal or cardiovascular outcomes (model 3).

SDNN and RMSSD were associated with all-cause mortality in both model 1 and model 2, but the relationship with all-cause mortality was nonlinear with increased risk observed for both low and high HRV (fig. 3). In fully adjusted models, low RMSSD was associated with increased risk for all-cause mortality [HR 1.26 (95\% CI $1.01-1.58)$ for a $50 \%$ decrease in RMSSD at the median $(\mathrm{p}=0.04)$ ], but, as in models 1 and 2 , the relationship with all-cause mortality was nonlinear with increased risk observed for both low and high HRV (fig. 3). There was a similar trend with SDNN, though it did not reach statistical significance $(\mathrm{p}=0.12)$.

Given the concern for overadjustment, backward stepwise selection was used to select adjustment variables for model 3 and the findings were consistent (data not shown). There were no violations of the proportion-

Am J Nephrol 2013;38:517-528 
Table 1. Baseline characteristics by quartiles of HRV (SDNN)

\begin{tabular}{|c|c|c|c|c|c|}
\hline & \multicolumn{4}{|c|}{ SDNN (HRV quartiles) } & $\mathrm{p}$ value \\
\hline SDNN & $5.4(1.8)$ & $11.4(1.8)$ & $19.5(3.0)$ & $44.4(22.8)$ & \\
\hline Age, years & $58.8(10.1)$ & $59.7(10.1)$ & $57.8(10.7)$ & $54.6(12.5)$ & $<0.001$ \\
\hline Gender & & & & & 0.50 \\
\hline Race & & & & & $<0.001$ \\
\hline Non-Hispanic white & $332(40.9)$ & $333(41.1)$ & $346(42.8)$ & $346(42.5)$ & \\
\hline Non-Hispanic black/African American & $286(35.3)$ & $325(40.1)$ & $339(41.9)$ & $368(45.2)$ & \\
\hline Hispanic & $160(19.7)$ & $111(13.7)$ & $100(12.4)$ & $60(7.4)$ & \\
\hline Other & $33(4.1)$ & $42(5.2)$ & $24(3.0)$ & $40(4.9)$ & \\
\hline High school education & $230(28.4)$ & $232(28.6)$ & $245(30.3)$ & $246(30.2)$ & \\
\hline$\geq$ College graduate & $218(26.9)$ & $241(29.7)$ & $265(32.8)$ & $301(37.0)$ & \\
\hline \multicolumn{6}{|l|}{ Tobacco use } \\
\hline Current smoker & $101(12.5)$ & $109(13.4)$ & $99(12.2)$ & $106(13.0)$ & 0.88 \\
\hline$>100$ cigarettes during lifetime & $445(54.9)$ & $445(54.9)$ & $425(52.5)$ & $434(53.3)$ & 0.72 \\
\hline \multicolumn{6}{|l|}{ Lifestyle modification, \% yes } \\
\hline Any & $773(95.3)$ & $767(94.6)$ & $744(92.0)$ & $720(88.5)$ & $<0.001$ \\
\hline Exercise & $524(64.9)$ & $550(68.1)$ & $596(73.9)$ & $631(77.5)$ & $<0.001$ \\
\hline \multicolumn{6}{|l|}{ Medical history } \\
\hline Hypertension & $732(90.3)$ & $701(86.4)$ & $687(84.9)$ & $655(80.5)$ & $<0.001$ \\
\hline Blood pressure $>130 / 80 \mathrm{~mm} \mathrm{Hg}$ & $445(54.9)$ & $403(49.7)$ & $412(50.9)$ & $447(54.9)$ & 0.001 \\
\hline BMI & $32.6(8.3)$ & $31.7(7.1)$ & $32.1(7.6)$ & $31.6(7.6)$ & 0.05 \\
\hline \multicolumn{6}{|l|}{ Kidney function measures } \\
\hline Adjusted serum creatinine, $\mathrm{mg} / \mathrm{dl}$ & $1.86(0.6)$ & $1.73(0.6)$ & $1.68(0.5)$ & $1.66(0.5)$ & $<0.001$ \\
\hline $\mathrm{eGFR}, \mathrm{ml} / \mathrm{min} / 1.73 \mathrm{~m}^{2}$ & $39.4(13)$ & $42.6(13)$ & $44.4(14)$ & $45.9(14)$ & $<0.001$ \\
\hline eGFR & & & & & $<0.001$ \\
\hline$<30 \mathrm{ml} / \mathrm{min} / 1.73 \mathrm{~m}^{2}$ & $223(27.5)$ & $158(19.5)$ & $131(16.2)$ & $119(14.6)$ & \\
\hline 30 to $<45 \mathrm{ml} / \mathrm{min} / 1.73 \mathrm{~m}^{2}$ & $314(38.7)$ & $308(38.0)$ & $286(35.4)$ & $288(35.4)$ & \\
\hline 45 to $<60 \mathrm{ml} / \mathrm{min} / 1.73 \mathrm{~m}^{2}$ & $227(28.0)$ & $273(33.7)$ & $292(36.1)$ & $272(33.4)$ & \\
\hline$\geq 60 \mathrm{ml} / \mathrm{min} / 1.73 \mathrm{~m}^{2}$ & $47(5.8)$ & $72(8.9)$ & $100(12.4)$ & $135(16.6)$ & \\
\hline Urine protein $/ 24 \mathrm{~h}, \mathrm{~g} / 24 \mathrm{~h}$ & $0.32(0.09-1.62)$ & $0.16(0.07-0.82)$ & $0.15(0.07-0.73)$ & $0.14(0.07-0.84)$ & $<0.001$ \\
\hline ACEI or ARB therapy & $580(71.9)$ & $540(67.4)$ & $552(68.5)$ & $535(66.2)$ & 0.08 \\
\hline$\beta$-Blocker therapy & $419(51.9)$ & $397(49.6)$ & $376(46.7)$ & $375(46.4)$ & 0.08 \\
\hline LDL cholesterol, mg/dl & $99.1(36)$ & $102.3(36)$ & $104.9(35)$ & $105.6(34)$ & $<0.001$ \\
\hline HDL cholesterol, mg/dl & $46.4(14)$ & $47.7(16)$ & $48.0(16)$ & $48.1(15)$ & 0.11 \\
\hline Triglycerides, mg/dl & $172(134)$ & $167(131)$ & $150(113)$ & $148(98)$ & $<0.001$ \\
\hline Hemoglobin, g/dl & $12.2(1.8)$ & $12.6(1.7)$ & $12.7(1.8)$ & $12.9(1.7)$ & $<0.001$ \\
\hline
\end{tabular}


Table 1 (continued)

\begin{tabular}{|c|c|c|c|c|c|}
\hline & \multicolumn{4}{|c|}{ SDNN (HRV quartiles) } & \multirow[t]{2}{*}{$\mathrm{p}$ value } \\
\hline & $\begin{array}{l}<8.5 \\
(\mathrm{n}=811)\end{array}$ & $\begin{array}{l}8.5 \text { to }<14.9 \\
(\mathrm{n}=811)\end{array}$ & $\begin{array}{l}14.9 \text { to }<25.5 \\
(\mathrm{n}=809)\end{array}$ & $\begin{array}{l}\geq 25.5 \\
(\mathrm{n}=814)\end{array}$ & \\
\hline Serum calcium, mg/dl & $9.10(0.5)$ & $9.20(0.5)$ & $9.21(0.5)$ & $9.21(0.5)$ & $<0.001$ \\
\hline Serum phosphorus, mg/dl & $3.91(0.7)$ & $3.77(0.7)$ & $3.65(0.6)$ & $3.61(0.6)$ & $<0.001$ \\
\hline Serum albumin, $\mathrm{g} / \mathrm{dl}$ & $3.85(0.5)$ & $3.97(0.5)$ & $3.95(0.5)$ & $4.00(0.4)$ & $<0.001$ \\
\hline Total iPTH, pg/ml & $60(38-104)$ & $51(34-83)$ & $52(35-85)$ & $49(32-80)$ & $<0.001$ \\
\hline FGF23, RU/ml & $174(116-284)$ & $142(95-226)$ & $131(88-212)$ & $118(84-204)$ & $<0.001$ \\
\hline Blood glucose, mg/dl & $110(91-153)$ & $98(87-127)$ & $95(87-113)$ & $93(84-111)$ & $<0.001$ \\
\hline Hemoglobin A1c, \% & $7.25(1.8)$ & $6.65(1.5)$ & $6.38(1.3)$ & $6.27(1.4)$ & $<0.001$ \\
\hline Insulin, $\mathrm{U} / \mathrm{ml}$ & $18(12-31)$ & $16(11-25)$ & $16(11-25)$ & $14(10-22)$ & $<0.001$ \\
\hline Serum uric acid, mg/dl & $7.5(1.9)$ & $7.4(1.9)$ & $7.3(1.9)$ & $7.2(1.9)$ & 0.02 \\
\hline C-reactive protein, $\mathrm{mg} / \mathrm{l}$ & $2.78(1.1-6.7)$ & $2.64(1.0-6.2)$ & $2.41(1.0-6.0)$ & $2.21(1.0-5.6)$ & 0.08 \\
\hline
\end{tabular}

Values are means \pm SD for continuous variables, medians and interquartile ranges for skewed variables, and $\mathrm{n}$ (\%) for categorical variables. $\mathrm{MI}=$ Myocardial infarction; $\mathrm{SBP}=$ systolic blood pressure; $\mathrm{DBP}=$ diastolic blood pressure; $\mathrm{ACEI}=$ angiotensin-converting enzyme inhibitor; $\mathrm{ARB}=$ angiotensin receptor blocker; $\mathrm{iPTH}=$ intact parathyroid hormone.

al hazard assumption and the relationship between log HRV and the log relative HR for adverse clinical outcomes was found to be linear. Secondary analysis of the components of the cardiovascular composite revealed that lower SDNN and RMSSD were associated with increased rates of congestive heart failure in models 1 and 2 (table 4) but not stroke or myocardial infarction. Results were similar when analyses were restricted to participants without cardiovascular disease at baseline (online suppl. table 3). Lower SDNN and RMSSD were not associated with ESRD in Cox models or in secondary analyses with death as a competing risk (online suppl. table 4). In fully adjusted models, neither SDNN nor RMSSD were associated with an increased relative HR for congestive heart failure. There were no significant interactions between HRV and age, gender, race, diabetes, coronary artery disease, eGFR, or proteinuria for any of the outcomes.

\section{Discussion}

In a large cohort of patients with CKD, multiple risk factors for renal and cardiovascular diseases including older age, diabetes, elevated phosphorus and hemoglobin A1c, and lower eGFR were associated with lower HRV. Lower SDNN and RMSSD were associated with increased risk for renal and cardiovascular outcomes and all-cause mortality independent of demographics, eGFR, and pro- teinuria. However, after additional adjustment for other confounding factors, neither SDNN nor RMSSD were independent risk factors for renal or cardiovascular outcomes. There was a nonlinear association between SDNN and RMSSD and all-cause mortality with increased risk with both low and high HRV; there was a significant increased relative hazard for all-cause mortality with both low and high RMSSD. Findings were consistent across subgroups by age, sex, diabetes, coronary artery disease, and renal function.

Our cross-sectional findings, in a large cohort of participants with CKD, are consistent with previous studies in that lower HRV was associated with older age and diabetes. A novel finding is the association between lower HRV and elevated phosphorus. Elevated phosphorus had previously been reported to be associated with another measure of HRV, the ratio of low-frequency to high-frequency power, but not with SDNN or RMSSD [17]. The effect of elevated phosphorus on HRV may be mediated through vascular calcification and arterial stiffness, which are associated with reduced baroreflex sensitivity [3335]. Elevated phosphorus is associated with elevated FGF23, which has direct effects on cardiomyocytes and increases left ventricular mass; these effects may partially explain the association between phosphorus and HRV [36]. In fact, heart failure was associated with low HRV at baseline; however, HRV was not associated with heart failure events in longitudinal analysis. 
Fig. 1. Unadjusted rate of clinical outcomes per 1,000 person years by quartile of HRV.
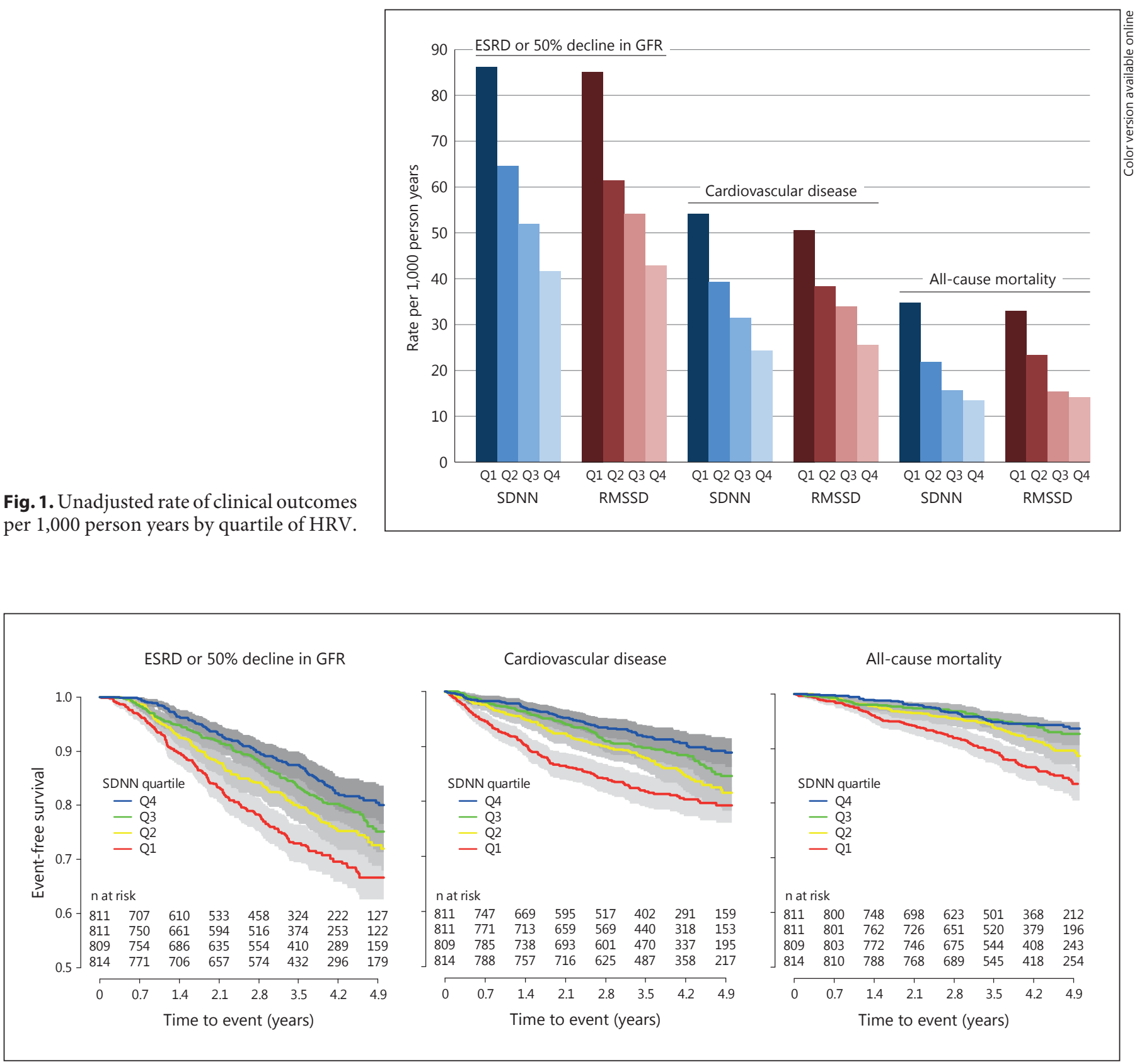

Fig. 2. Event-free survival by SDNN quartiles for the renal outcome, cardiovascular outcome, and all-cause mortality.

Previous studies have revealed a relatively consistent relationship between HRV and both eGFR and proteinuria in cross-sectional analyses [3-9]. Potential causes of decreased HRV in CKD include renal ischemia, reduced nitric oxide, and uremic toxins [1]. Prior studies have been restricted by small sample sizes or limited numbers of participants with CKD. Our results, in a large sample of patients with a wide range of $\mathrm{CKD}$, confirm that lower eGFR is associated with lower HRV even in multivariable models. However, in the present study, proteinuria was not associated with lower HRV. This is in contrast to previous studies which found lower HRV to be associated with elevated levels of proteinuria [5-7]. These prior studies differed in that they were evaluating the relation- 
Table 2. Multivariable associations between HRV and baseline clinical and demographic characteristics

\begin{tabular}{|c|c|c|c|c|}
\hline & \multicolumn{2}{|l|}{$\mathrm{SDNN}^{\mathrm{a}}$} & \multicolumn{2}{|l|}{$\mathrm{RMSSD}^{\mathrm{a}}$} \\
\hline Gender, male vs. female & $-0.22(0.05)$ & $<0.001$ & $-0.32(0.05)$ & $<0.001$ \\
\hline \multicolumn{5}{|l|}{ Race, vs. non-Hispanic white } \\
\hline Non-Hispanic black/African American & $0.28(0.05)$ & $<0.001$ & $0.39(0.05)$ & $<0.001$ \\
\hline \multicolumn{5}{|l|}{ Education, vs. <high school } \\
\hline High school diploma & $-0.04(0.07)$ & 0.57 & $-0.06(0.06)$ & 0.33 \\
\hline High school education & $-0.03(0.06)$ & 0.59 & $-0.08(0.06)$ & 0.20 \\
\hline$\geq$ College graduate & $0.04(0.07)$ & 0.54 & $-0.02(0.06)$ & 0.80 \\
\hline \multicolumn{5}{|l|}{ Smoking status, vs. non-smoker } \\
\hline \multicolumn{5}{|l|}{ Medical history } \\
\hline Hypertension & $-0.03(0.07)$ & 0.64 & $-0.01(0.07)$ & 0.83 \\
\hline MI or coronary revascularization & $-0.02(0.05)$ & 0.60 & $-0.04(0.05)$ & 0.40 \\
\hline Chronic heart failure & $-0.16(0.07)$ & 0.03 & $-0.15(0.07)$ & 0.04 \\
\hline Diabetes $\left(e G F R=30 \mathrm{ml} / \mathrm{min} / 1.73 \mathrm{~m}^{2}\right)^{\mathrm{c}}$ & $-0.18(0.07)$ & 0.03 & $-0.16(0.07)$ & 0.03 \\
\hline Diabetes $\left(e G F R=60 \mathrm{ml} / \mathrm{min} / 1.73 \mathrm{~m}^{2}\right)$ & $-0.01(0.08)$ & & $0.04(0.08)$ & \\
\hline Heart rate & $-0.03(0.01)^{b}$ & $<0.001$ & $-0.06(0.002)$ & $<0.001$ \\
\hline Systolic blood pressure & $-0.005(0.003)^{b}$ & 0.18 & $-0.005(0.003)^{b}$ & 0.07 \\
\hline BMI & $0.01(0.003)$ & 0.001 & $0.01(0.003)$ & $<0.001$ \\
\hline \multicolumn{5}{|l|}{ Kidney function measures } \\
\hline eGFR $(\text { diabetes }=\text { yes })^{c}$ & $0.01(0.003)$ & $<0.001$ & $0.01(0.002)$ & $<0.001$ \\
\hline Hemoglobin & $0.01(0.01)$ & 0.35 & $0.01(0.01)$ & 0.45 \\
\hline Serum calcium & $-0.02(0.07)^{b}$ & 0.09 & $-0.03(0.07)^{b}$ & 0.17 \\
\hline Serum phosphorus & $-0.19(0.03)$ & $<0.001$ & $-0.18(0.03)$ & $<0.001$ \\
\hline Serum albumin & $-0.002(0.06)$ & 0.97 & $-0.01(0.06)$ & 0.87 \\
\hline Total iPTH & $0.0(0.0004)$ & 0.97 & $-0.0003(0.0004)$ & 0.41 \\
\hline FGF23 & $0.0(0.0)$ & 0.98 & $0.0(0.0)$ & 0.92 \\
\hline Hemoglobin A1c & $-0.14(0.05)^{\mathrm{b}}$ & $<0.001$ & $-0.14(0.04)^{\mathrm{b}}$ & $<0.001$ \\
\hline Insulin & $0.0(0.001)$ & 0.97 & $-0.0001(0.001)$ & 0.88 \\
\hline Uric acid & $-0.0002(0.01)$ & 0.98 & $0.006(0.01)$ & 0.62 \\
\hline C-reactive protein & $-0.005(0.01)$ & 0.70 & $-0.004(0.01)$ & 0.72 \\
\hline
\end{tabular}

Models adjusted for all variables shown in the table. $\beta$ (SE) for 1 -unit increase. Bold indicates $\mathrm{p}<0.05$. MI $=\mathrm{Myocardial}$ infarction; $\mathrm{ACEI}=$ angiotensin-converting enzyme inhibitor; $\mathrm{ARB}=$ angiotensin receptor blocker; $\mathrm{iPTH}=$ intact parathyroid hormone.

${ }^{\mathrm{a}} \log (2)$ transformed.

${ }^{\mathrm{b}}$ Nonlinear, $\beta$ (SE) for 1-unit increase at median.

${ }^{c}$ Diabetes $\times$ eGFR interaction, $\mathrm{p}=0.05$ for SDNN and $\mathrm{p}=0.02$ for RMSSD. 


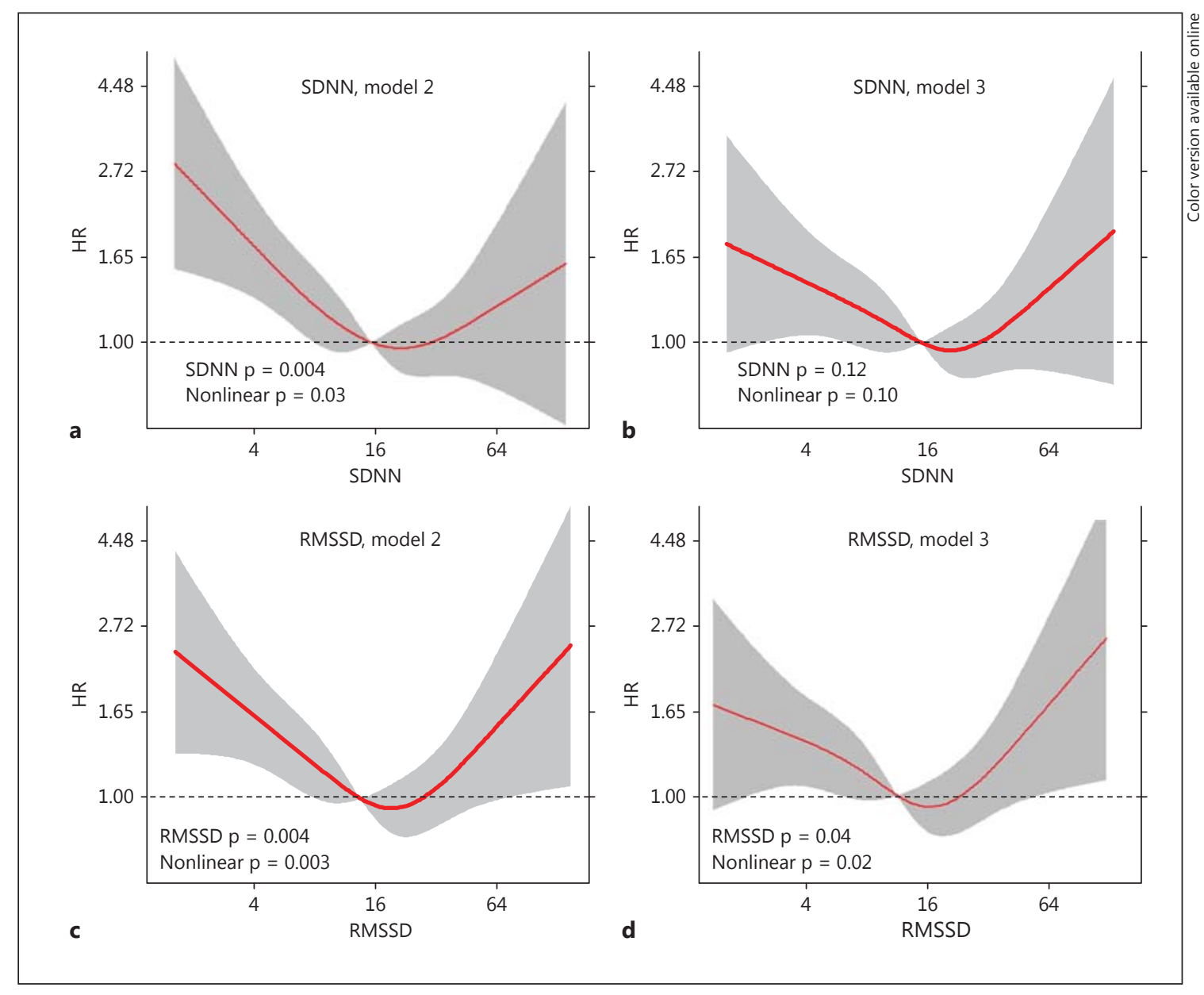

Fig. 3. Nonlinear relative hazard for all-cause mortality for SDNN and RMSSD.

ship in subjects with normal to mild albuminuria. At these low levels of albuminuria, lower HRV may be a subclinical marker of CKD whereas in those with overt $\mathrm{CKD}$, as in the present study, HRV and proteinuria may not be associated. Further research is necessary to better understand the causal relationship between CKD and low HRV.

In longitudinal analyses, lower HRV was associated with renal outcomes independent of eGFR and proteinuria, but it was not associated with renal outcomes in multivariable models. This is in contrast to results from the ARIC (Atherosclerosis Risk in Communities) study, in which low HRV was associated with both ESRD and ICD-9 code-based CKD hospitalization [21]. In the general population, low HRV could be a marker of subclinical CKD and renal ischemia and therefore be associated with increased risk for renal outcomes. Low HRV may also directly contribute to renal function decline via effects on hypertension and diabetes, both of which improve with renal nerve ablation [37]. However, in the present study of patients with overt CKD, low HRV was not associated with renal outcomes. Similar results were noted in the Renal Research Institute CKD Study, in which SDNN and RMSSD were not associated with ESRD in multivariable models, but a frequency domain measure of HRV was associated with ESRD in multivariable models [17]. A potential explanation for the lack of association between HRV and ESRD in these CKD patients is that the underlying risk of ESRD is high enough that HRV does not have any additive predictive value. Despite our findings in multivariable models, it is significant that lower HRV was associated with renal outcome independent of eGFR and proteinuria, two of the most important risk factors for CKD and ESRD. 
Table 3. Adjusted associations between baseline HRV and adverse clinical outcomes [HR $\left.{ }^{\mathrm{a}}(95 \% \mathrm{CI})\right]$

\begin{tabular}{|c|c|c|c|}
\hline & $\begin{array}{l}\text { ESRD or } \\
50 \% \text { decline in eGFR }\end{array}$ & Cardiovascular disease $^{\mathrm{b}}$ & All-cause mortality \\
\hline \multicolumn{4}{|l|}{ SDNN } \\
\hline Model 1 & $1.28(1.18-1.38)$ & $1.23(1.13-1.35)$ & $1.38(1.12-1.70)^{c}$ \\
\hline Model 2 & $1.08(1.00-1.17)$ & $1.17(1.06-1.29)$ & $1.26(1.02-1.56)^{c}$ \\
\hline Model 3 & $0.96(0.88-1.05)$ & $1.02(0.92-1.13)$ & $1.22(0.97-1.52)^{c}$ \\
\hline \multicolumn{4}{|l|}{ RMSSD } \\
\hline Model 1 & $1.28(1.18-1.39)$ & $1.19(1.08-1.31)$ & $1.42(1.16-1.75)^{\mathrm{d}}$ \\
\hline Model 2 & $1.09(1.00-1.19)$ & $1.13(1.02-1.25)$ & $1.31(1.06-1.62)^{\mathrm{d}}$ \\
\hline Model 3 & $0.97(0.88-1.07)$ & $1.00(0.90-1.10)$ & $1.26(1.01-1.58)^{\mathrm{d}}$ \\
\hline
\end{tabular}

Model 1 = Adjusted for age, gender, race, pulse (from ECG), and clinical center; model $2=$ model $1+$ BMI, eGFR, and proteinuria; model 3 = model 2 + systolic blood pressure, education, tobacco use, lifestyle modification, exercise, angiotensin-converting enzyme inhibitor/angiotensin receptor blocker use, $\beta$-blocker use, hypertension, coronary artery disease, diabetes, congestive heart failure, serum levels of calcium, phosphorus, uric acid, and albumin, FGF23, LDL and HDL cholesterol, triglycerides, and C-reactive protein.

${ }^{a}$ HR per 50\% decrease in SDNN and RMSSD [1-unit decrease in $\log (2)$ SDNN/RMSSD], bold indicates $\mathrm{p}<$ 0.05 .

${ }^{\mathrm{b}}$ Cardiovascular disease composite includes myocardial infarction, congestive heart failure, and cerebrovascular accident.

${ }^{c} \mathrm{p}$ value for nonlinear terms: 0.02 for model 1 and 0.03 for model 2 , and 0.10 for model 3; HR per $50 \%$ decrease at median.

${ }^{d} \mathrm{p}$ value for nonlinear terms: $<0.001$ for model 1, 0.003 for model 2 , and 0.02 for model 3; HR per $50 \%$ decrease at median.

Table 4. Adjusted associations between baseline HRV and specific adverse clinical outcomes [HR $\left.{ }^{\mathrm{a}}(95 \% \mathrm{CI})\right]$

\begin{tabular}{lllll}
\hline & ESRD & Myocardial infarction & Heart failure & Stroke \\
\hline SDNN & & & & \\
Model 1 & $\mathbf{1 . 2 8 ( 1 . 1 7 - 1 . 4 0 )}$ & $1.09(0.93-1.28)$ & $\mathbf{1 . 3 0}(\mathbf{1 . 1 6}-\mathbf{1 . 4 6})$ & $1.16(0.95-1.43)$ \\
Model 2 & $1.05(0.95-1.15)$ & $1.06(0.90-1.25)$ & $\mathbf{1 . 2 2}(\mathbf{1 . 0 9 - 1 . 3 8 )}$ & $1.21(0.97-1.51)$ \\
Model 3 & $0.96(0.86-1.06)$ & $0.96(0.81-1.14)$ & $1.03(0.91-1.16)$ & $1.09(0.87-1.38)$ \\
RMSSD & & & & \\
Model 1 & $\mathbf{1 . 5 2 ( 1 . 3 0 - 1 . 7 9 )}$ & $1.03(0.87-1.21)$ & $\mathbf{1 . 4 0}(\mathbf{1 . 1 4 - 1 . 7 1})^{\mathrm{c}}$ & $1.20(0.97-1.49)$ \\
Model 2 & $1.08(0.97-1.19)$ & $0.98(0.83-1.16)$ & $\mathbf{1 . 1 8 ( 1 . 0 5 - 1 . 3 3 )}$ & $1.24(0.98-1.56)$ \\
Model 3 & $0.97(0.87-1.09)$ & $0.90(0.76-1.07)$ & $1.02(0.90-1.15)$ & $1.18(0.93-1.50)$ \\
\hline
\end{tabular}

See table 3 for abbreviations and variables included in each model.

${ }^{a}$ HR per 50\% decrease in SDNN and RMSSD, bold indicates $\mathrm{p}<0.05$.

${ }^{\mathrm{b}} \mathrm{p}$ value for nonlinear terms: 0.04 for model 1 ; HR per $50 \%$ decrease at median.

${ }^{c}$ p value for nonlinear terms: 0.05 for model 1; HR per $50 \%$ decrease at median.

Lower HRV is a well-established risk factor for cardiovascular disease and all-cause mortality in the general population; smaller studies have indicated a similar risk in patients with CKD and ESRD [16, 17, 19, 20, 22-24]. Previous studies in subjects with renal dysfunction were limited by inclusion of only mild or severe CKD or small sample sizes, which limits adjustment for important po- tential confounders. Among the CRIC participants who had a wide range of CKD, lower HRV was not associated with increased risk for cardiovascular outcome in fully adjusted models. It may be difficult to detect an effect of lower HRV on these outcomes because of the substantial and significant associations of HRV with several major confounders. 
Importantly, a nonlinear association was observed between HRV and all-cause mortality, which was significant for HRV measured by RMSSD $(\mathrm{p}=0.04)$ but only marginally significant for SDNN ( $\mathrm{p}=0.12)$. Most previous studies assumed or found a linear relationship between HRV and adverse outcomes. However, our finding of a nonlinear association with all-cause mortality is consistent with a previous study in which risk for all-cause mortality was observed for participants in both the first and fourth quartiles of HRV [38]. As discussed above, increased risk for all-cause mortality with low HRV is likely due to increased sympathetic and decreased parasympathetic activity. Increased risk for all-cause mortality with elevated HRV may be a reflection of underlying sinoatrial node dysfunction $[39,40]$. Our findings that HRV predicted mortality, but not cardiovascular events and progression of renal disease, raises the possibility that the risk associated with HRV may be mediated by dysrhythmias and sudden cardiac death rather than traditional atherosclerotic cardiovascular disease. However, this is speculative at this time and will require further research.

Decreased HRV may be more than a predictor of adverse outcomes - it is modifiable and may be used as a therapeutic target. In the Diabetes Prevention Program trial, the intensive lifestyle intervention program led to improvement in HRV [29]. A number of other studies have shown that exercise programs increase HRV in dialysis patients and the elderly, and may in part explain the benefit of cardiac rehabilitation after myocardial infarction $[41,42]$. In fact, in the present study, exercise was associated with elevated SDNN and RMSSD in multivariable models.

This is the largest study of the association between HRV and adverse clinical outcomes in participants with $\mathrm{CKD}$. Strengths of this study include a wide range of CKD and the large sample size. Extensive baseline assessment allowed for evaluation of the association between multiple covariates and comorbidities and HRV, as well as the ability to adjust for these variables in longitudinal analyses. Outcomes were carefully adjudicated by investigators per CRIC protocols. This study makes an important contribution to the literature by demonstrating that while lower HRV may be an important risk factor for adverse outcomes, it is not an independent risk factor for renal and cardiovascular outcomes in this well-defined cohort. This study also suggests that HRV is associated with multiple traditional atherosclerotic risk factors and demonstrates the importance of adequate adjustment for covariates in studying the association between HRV and clinical outcomes. Importantly, we demonstrate that HRV, mea- sured by RMSSD, is a novel and independent risk factor for mortality in CKD patients.

The main limitation of the study is the use of one 10-second ECG to evaluate HRV, which precludes evaluation of longer-term HRV such as low frequency and most likely reflects only parasympathetic cardiac modulation, and may be affected by artifacts. Additionally, HRV from a 10 -second ECG has a lower correlation with 24-hour measurements than longer recordings and is less reproducible [43]. Among CRIC participants, the correlation between baseline SDNN and the average SDNN at the 1- and 2-year follow-up visits was 0.55 ; for RMSSD, the correlation was 0.59 . Paced breathing, which may minimize respiratory influences on HRV, was not implemented. While a 5-min ECG tracing is recommended [30], cardiac autonomic neuropathy from a 10-second ECG was associated with cardiac and all-cause mortality in ACCORD [44] and coronary heart disease mortality in the Women's Health Initiative [45]. Additionally, use of 10-second ECGs is practi$\mathrm{cal}$ as they are commonly obtained in clinical practice. Risk for cardiovascular mortality was not evaluated because cause of death is not available at this time. The ability to generalize these results to all patients with CKD is somewhat limited because the cohort was referred or identified from clinical databases. This is an observational study which limits our ability to assess causality.

In conclusion, multiple renal and cardiovascular risk factors are associated with lower HRV in a large cohort of participants with CKD. Lower HRV was not a predictor of renal or cardiovascular outcomes. However, HRV measured by RMSSD is an independent predictor of mortality. This relationship is nonlinear, both lower and higher levels of RMSSD were associated with increased risk for all-cause mortality.

\section{Acknowledgment}

The study was supported in part through a Career Development Award K23DK087919 (P.E.D.) from the National Institute of Diabetes and Digestive and Kidney Diseases. The content is solely the responsibility of the authors and does not necessarily represent the official views of the National Institute of Diabetes and Digestive and Kidney Diseases or the National Institutes of Health. Funding for the CRIC Study was obtained under a cooperative agreement from the National Institute of Diabetes and Digestive and Kidney Diseases (U01DK060990, U01DK060984, U01DK061022, U01DK061021, U01DK061028, U01DK060980, U01DK060963 and U01DK060902). In addition, this work was supported in part by: the Perelman School of Medicine at the University of Pennsylvania Clinical and Translational Science Award (NIH/NCATS UL1TR000003), Johns Hopkins University (UL1 TR-000424), University of Maryland (GCRC M01 
RR-16500), Clinical and Translational Science Collaborative of Cleveland (UL1TR000439) from the National Center for Advancing Translational Sciences component of the National Institutes of Health and NIH roadmap for Medical Research, Michigan Institute for Clinical and Health Research (UL1TR000433), University of Illinois at Chicago Clinical and Translational Science Award (UL1RR029879), Tulane University Translational Research in Hypertension and Renal Biology (P30GM103337), and Kaiser Permanente(NIH/NCRRUCSF-CTSIUL1RR-024131 and K01DK092353).

\section{Disclosure Statement}

The authors have no financial relationships to disclose.

\section{References}

1 Schlaich MP, Socratous F, Hennebry S, Eikelis N, Lambert EA, Straznicky N, Esler MD, Lambert GW: Sympathetic activation in chronic renal failure. J Am Soc Nephrol 2009; 20:933-939.

$>2$ Converse RL Jr, Jacobsen TN, Toto RD, Jost CM, Cosentino F, Fouad-Tarazi F, Victor RG: Sympathetic overactivity in patients with chronic renal failure. N Engl J Med 1992;327: 1912-1918.

-3 Molgaard H, Christensen PD, Hermansen K, Sorensen KE, Christensen CK, Mogensen CE: Early recognition of autonomic dysfunction in microalbuminuria: significance for cardiovascular mortality in diabetes mellitus? Diabetologia 1994;37:788-796.

-4 Burger AJ, D’Elia JA, Weinrauch LA, Lerman I, Gaur A: Marked abnormalities in heart rate variability are associated with progressive deterioration of renal function in type I diabetic patients with overt nephropathy. Int J Cardiol 2002;86:281-287.

$\checkmark 5$ Poulsen PL, Ebbehoj E, Hansen KW, Mogensen CE: 24-h blood pressure and autonomic function is related to albumin excretion within the normoalbuminuric range in IDDM patients. Diabetologia 1997;40:718725.

6 Smulders YM, Jager A, Gerritsen J, Dekker JM, Nijpels G, Heine RJ, Bouter LM, Stehouwer CD: Cardiovascular autonomic function is associated with (micro-)albuminuria in elderly Caucasian subjects with impaired glucose tolerance or type 2 diabetes: the Hoorn Study. Diabetes Care 2000;23:1369-1374.

$>7$ Wirta OR, Pasternack AI, Mustonen JT, Laippala PJ, Reinikainen PM: Urinary albumin excretion rate is independently related to autonomic neuropathy in type 2 diabetes mellitus. J Intern Med 1999;245:329-335.

$>8$ Yang YW, Wu CH, Tsai MK, Kuo TB, Yang $\mathrm{CC}$, Lee PH: Heart rate variability during hemodialysis and following renal transplantation. Transplant Proc 2010;42:1637-1640.

$>9$ Liu M, Takahashi H, Morita Y, Maruyama S, Mizuno M, Yuzawa Y, Watanabe M, Toriyama T, Kawahara H, Matsuo S: Non-dipping is a potent predictor of cardiovascular mortality and is associated with autonomic dysfunction in haemodialysis patients. Nephrol Dial Transplant 2003;18:563-569.
10 Campese VM, Romoff MS, Levitan D, Lane K, Massry SG: Mechanisms of autonomic nervous system dysfunction in uremia. Kidney Int 1981;20:246-253.

11 Zilch O, Vos PF, Oey PL, Cramer MJ, Ligtenberg G, Koomans HA, Blankestijn PJ: Sympathetic hyperactivity in haemodialysis patients is reduced by short daily haemodialysis. $\mathrm{J} \mathrm{Hy}$ pertens 2007;25:1285-1289.

12 Rubinger D, Sapoznikov D, Pollak A, Popovtzer MM, Luria MH: Heart rate variability during chronic hemodialysis and after renal transplantation: studies in patients without and with systemic amyloidosis. J Am Soc Nephrol 1999;10:1972-1981.

-13 Mylonopoulou M, Tentolouris N, Antonopoulos S, Mikros S, Katsaros K, Melidonis A, Sevastos N, Katsilambros N: Heart rate variability in advanced chronic kidney disease with or without diabetes: midterm effects of the initiation of chronic haemodialysis therapy. Nephrol Dial Transplant 2010;25:37493754.

14 Rennie KL, Hemingway H, Kumari M, Brunner E, Malik M, Marmot M: Effects of moderate and vigorous physical activity on heart rate variability in a British study of civil servants. Am J Epidemiol 2003;158:135-143.

15 Liao D, Cai J, Brancati FL, Folsom A, Barnes RW, Tyroler HA, Heiss G: Association of vagal tone with serum insulin, glucose, and diabetes mellitus - the ARIC study. Diabetes Res Clin Pract 1995;30:211-221.

16 Dekker JM, Crow RS, Folsom AR, Hannan PJ, Liao D, Swenne CA, Schouten EG: Low heart rate variability in a 2-minute rhythm strip predicts risk of coronary heart disease and mortality from several causes: the ARIC study. Atherosclerosis Risk in Communities. Circulation 2000;102:1239-1244.

17 Chandra P, Sands RL, Gillespie BW, Levin NW, Kotanko P, Kiser M, Finkelstein F, Hinderliter A, Pop-Busui R, Rajagopalan S, Saran R: Predictors of heart rate variability and its prognostic significance in chronic kidney disease. Nephrol Dial Transplant 2012;27: 700-709.
18 Stein PK, Barzilay JI, Chaves PH, Traber J, Domitrovich PP, Heckbert SR, Gottdiener JS: Higher levels of inflammation factors and greater insulin resistance are independently associated with higher heart rate and lower heart rate variability in normoglycemic older individuals: the Cardiovascular Health Study. J Am Geriatr Soc 2008;56:315-321.

19 Liao D, Cai J, Rosamond WD, Barnes RW, Hutchinson RG, Whitsel EA, Rautaharju P, Heiss G: Cardiac autonomic function and incident coronary heart disease: a populationbased case-cohort study. The ARIC study. Atherosclerosis Risk in Communities study. Am J Epidemiol 1997;145:696-706.

20 Tsuji H, Larson MG, Venditti FJ Jr, Manders ES, Evans JC, Feldman CL, Levy D: Impact of reduced heart rate variability on risk for cardiac events. The Framingham Heart Study. Circulation 1996;94:2850-2855.

21 Brotman DJ, Bash LD, Qayyum R, Crews D, Whitsel EA, Astor BC, Coresh J: Heart rate variability predicts ESRD and CKD-related hospitalization. J Am Soc Nephrol 2010;21: 1560-1570.

22 Fukuta H, Hayano J, Ishihara S, Sakata S, Mukai S, Ohte N, Ojika K, Yagi K, Matsumoto H, Sohmiya S, Kimura G: Prognostic value of heart rate variability in patients with endstage renal disease on chronic haemodialysis. Nephrol Dial Transplant 2003;18:318-325.

23 Oikawa K, Ishihara R, Maeda T, Yamaguchi K, Koike A, Kawaguchi H, Tabata Y, Murotani N, Itoh H: Prognostic value of heart rate variability in patients with renal failure on hemodialysis. Int J Cardiol 2009;131:370-377.

-24 Astrup AS, Tarnow L, Rossing P, Hansen BV, Hilsted J, Parving HH: Cardiac autonomic neuropathy predicts cardiovascular morbidity and mortality in type 1 diabetic patients with diabetic nephropathy. Diabetes Care 2006;29:334-339.

25 Rahman M, Pressel S, Davis BR, Nwachuku C, Wright JT Jr, Whelton PK, Barzilay J, Batuman V, Eckfeldt JH, Farber MA, Franklin S, Henriquez M, Kopyt N, Louis GT, Saklayen M, Stanford C, Walworth C, Ward H, Wiegmann T: Cardiovascular outcomes in highrisk hypertensive patients stratified by baseline glomerular filtration rate. Ann Intern Med 2006;144:172-180. 
-26 Feldman HI, Appel LJ, Chertow GM, Cifelli D, Cizman B, Daugirdas J, Fink JC, FranklinBecker ED, Go AS, Hamm LL, He J, Hostetter T, Hsu CY, Jamerson K, Joffe M, Kusek JW, Landis JR, Lash JP, Miller ER, Mohler ER 3rd, Muntner P, Ojo AO, Rahman M, Townsend RR, Wright JT: The Chronic Renal Insufficiency Cohort (CRIC) study: design and methods. J Am Soc Nephrol 2003;14:S148S153.

27 Lash JP, Go AS, Appel LJ, He J, Ojo A, Rahman M, Townsend RR, Xie D, Cifelli D, Cohan J, Fink JC, Fischer MJ, Gadegbeku C, Hamm LL, Kusek JW, Landis JR, Narva A, Robinson N, Teal V, Feldman HI: Chronic Renal Insufficiency Cohort (CRIC) study: baseline characteristics and associations with kidney function. Clin J Am Soc Nephrol 2009; 4:1302-1311.

28 Levey AS, Coresh J, Greene T, Marsh J, Stevens LA, Kusek JW, Van Lente F: Expressing the Modification of Diet in Renal Disease study equation for estimating glomerular filtration rate with standardized serum creatinine values. Clin Chem 2007;53:766-772.

-29 Carnethon MR, Prineas RJ, Temprosa M, Zhang ZM, Uwaifo G, Molitch ME: The association among autonomic nervous system function, incident diabetes, and intervention arm in the Diabetes Prevention Program. Diabetes Care 2006;29:914-919.

30 Heart rate variability: standards of measurement, physiological interpretation and clinical use. Task Force of the European Society of Cardiology and the North American Society of Pacing and Electrophysiology. Circulation 1996;93:1043-1065.

31 Derksen S, Keselman HJ: Backward, forward and stepwise automated subset selection algorithms: frequency of obtaining authentic and noise variables. Br J Math Stat Psychol 1992; 45:265-282.
-32 Liao D, Carnethon M, Evans GW, Cascio WE, Heiss G: Lower heart rate variability is associated with the development of coronary heart disease in individuals with diabetes: the Atherosclerosis Risk in Communities (ARIC) study. Diabetes 2002;51:3524-3531.

- 33 Townsend RR, Wimmer NJ, Chirinos JA, Parsa A, Weir M, Perumal K, Lash JP, Chen J, Steigerwalt SP, Flack J, Go AS, Rafey M, Rahman M, Sheridan A, Gadegbeku CA, Robinson NA, Joffe M: Aortic PWV in chronic kidney disease: a CRIC ancillary study. Am J Hypertens 2010;23:282-289.

34 Monahan KD, Dinenno FA, Seals DR, Clevenger CM, Desouza CA, Tanaka H: Ageassociated changes in cardiovagal baroreflex sensitivity are related to central arterial compliance. Am J Physiol Heart Circ Physiol 2001;281:H284-H289.

35 Okada Y, Galbreath MM, Shibata S, Jarvis SS, VanGundy TB, Meier RL, Vongpatanasin W, Levine BD, Fu Q: Relationship between sympathetic baroreflex sensitivity and arterial stiffness in elderly men and women. Hypertension 2012;59:98-104.

36 Faul C, Amaral AP, Oskouei B, Hu MC, Sloan A, Isakova T, Gutierrez OM, Aguillon-Prada R, Lincoln J, Hare JM, Mundel P, Morales A, Scialla J, Fischer M, Soliman EZ, Chen J, Go AS, Rosas SE, Nessel L, Townsend RR, Feldman HI, St John Sutton M, Ojo A, Gadegbeku C, Di Marco GS, Reuter S, Kentrup D, Tiemann K, Brand M, Hill JA, Moe OW, Kuro OM, Kusek JW, Keane MG, Wolf M: FGF23 induces left ventricular hypertrophy. J Clin Invest 2011;121:4393-4408.

- 37 Krum H, Sobotka P, Mahfoud F, Böhm M, Esler M, Schlaich M: Device-based antihypertensive therapy: Therapeutic modulation of the autonomic nervous system. Circulation 2011;123:209-215.
8 de Bruyne MC, Kors JA, Hoes AW, Klootwijk P, Dekker JM, Hofman A, van Bemmel JH, Grobbee DE: Both decreased and increased heart rate variability on the standard 10 -second electrocardiogram predict cardiac mortality in the elderly: the Rotterdam Study. Am J Epidemiol 1999;150:1282-1288.

39 Sosnowski M, Petelenz T: Heart rate variability. Is it influenced by disturbed sinoatrial node function? J Electrocardiol 1995;28:245251.

40 Roberts-Thomson KC, Sanders P, Kalman JM: Sinus node disease: an idiopathic right atrial myopathy. Trends Cardiovasc Med 2007;17:211-214.

41 Deligiannis A, Kouidi E, Tourkantonis A: Effects of physical training on heart rate variability in patients on hemodialysis. Am J Cardiol 1999;84:197-202.

42 Albinet CT, Boucard G, Bouquet CA, Audiffren $\mathrm{M}$ : Increased heart rate variability and executive performance after aerobic training in the elderly. Eur J Appl Physiol 2010;109: 617-624.

-43 Schroeder EB, Whitsel EA, Evans GW, Prineas RJ, Chambless LE, Heiss G: Repeatability of heart rate variability measures. J Electrocardiol 2004;37:163-172.

44 Pop-Busui R, Evans GW, Gerstein HC, Fonseca V, Fleg JL, Hoogwerf BJ, Genuth S, Grimm RH, Corson MA, Prineas R, ACCORD Study Group: Effects of cardiac autonomic dysfunction on mortality risk in the Action to Control Cardiovascular Risk in Diabetes (ACCORD) trial. Diabetes Care 2010; 33:1578-1584.

45 Rautaharju PM, Kooperberg C, Larson JC, LaCroix A: Electrocardiographic abnormalities that predict coronary heart disease events and mortality in postmenopausal women: the Women's Health Initiative. Circulation 2006; 113:473-480 